\title{
Estratégias para melhorar o faturamento: promovendo a sustentabilidade financeira
}

Autores: Renato Madrid Baldassare, Greta Mascherpe Rossini, Heloisa Helena Piva, Priscila Tagliaferro Rojo

\section{Introdução}

A sustentabilidade financeira está entre as principais preocupações dos gestores. Os últimos anos têm sido marcados pela escassez de recursos, exigindo diversas ações para minimizar os impactos na assistência. Uma das ações é criar rotinas que assegurem o faturamento dos procedimentos realizados. Um diagnóstico realizado pelo Grupo de Gestão mostrou que muitos procedimentos não são faturados por falhas nos processos de registro, impactando o resultado financeiro apresentado pelo Hospital das Clínicas à Secretaria de Estado da Saúde.

\section{Método}

Foram utilizadas ferramentas da qualidade para análise da causa e elaboração dos planos de ação.

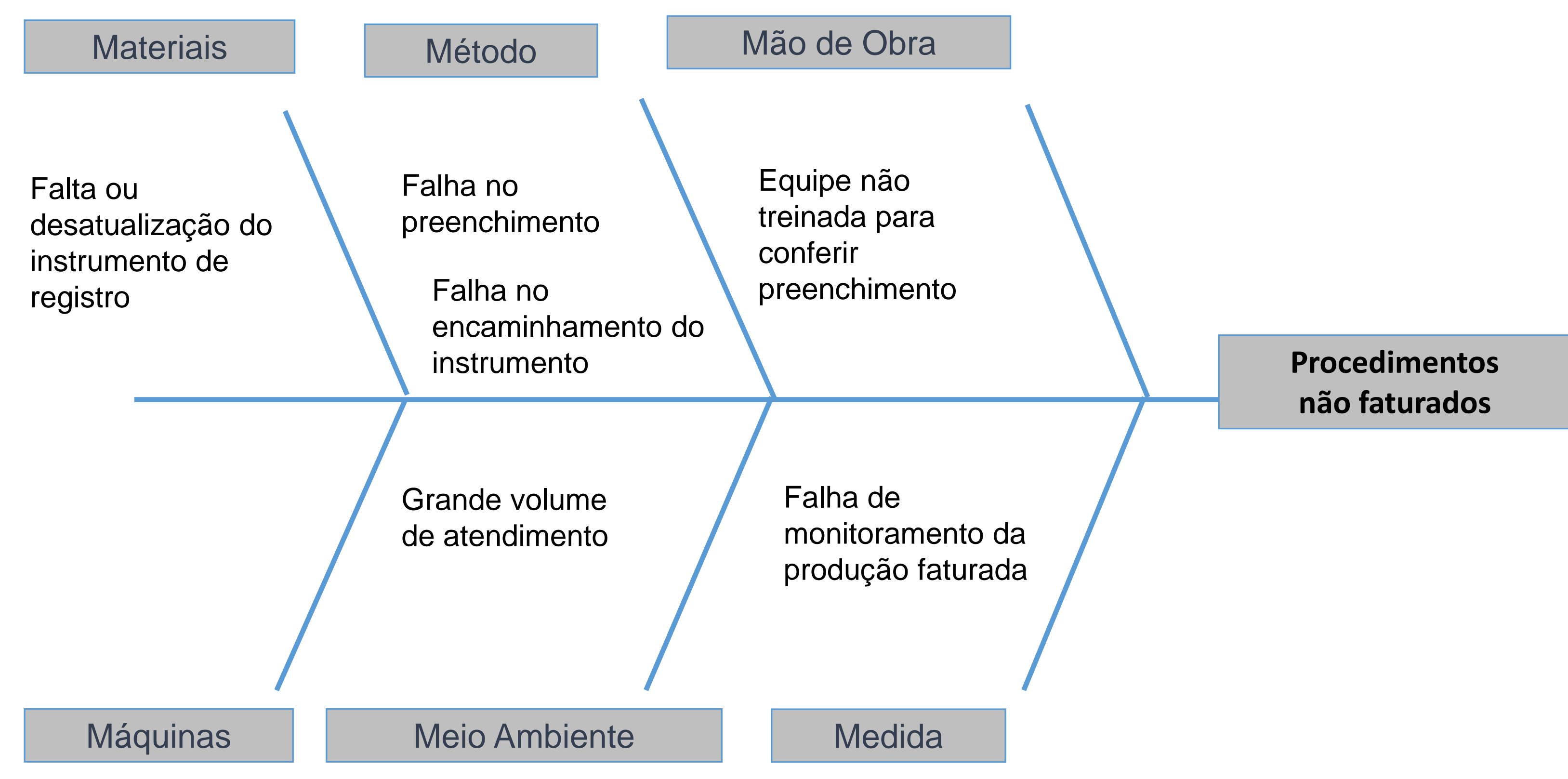

A partir das causas identificadas, o projeto buscou revisar o processo de faturamento ambulatorial SUS das especialidades do Grupo de Gestão, seguindo as etapas abaixo.

Levantamento de dados de Produção Acumulada e PRO_AUT

Revisão do rol de procedimentos realizados

Criação/Atualização da Ficha de Faturamento Ambulatorial

Treinamento das equipes médica e administrativa

Implantação da Ficha de Faturamento Ambulatorial revisada

\section{Resultados}

Após desenvolvimento das ações, foram implantadas as Fichas de Faturamento Ambulatorial e aquelas que já possuíam instrumento de registro foram revisadas e atualizadas. As equipes médicas e administrativas foram orientadas e sensibilizadas quanto ao preenchimento e encaminhamento do instrumento. Como resultados, houve aumento importante nos valores mensais de faturamento, passando de uma média mensal $R \$ 188$ mil ( $1^{\circ}$ semestre/18) para $R \$ 235$ mil (média $2^{\circ}$ semestre/18), representando um aumento de $25 \%$.

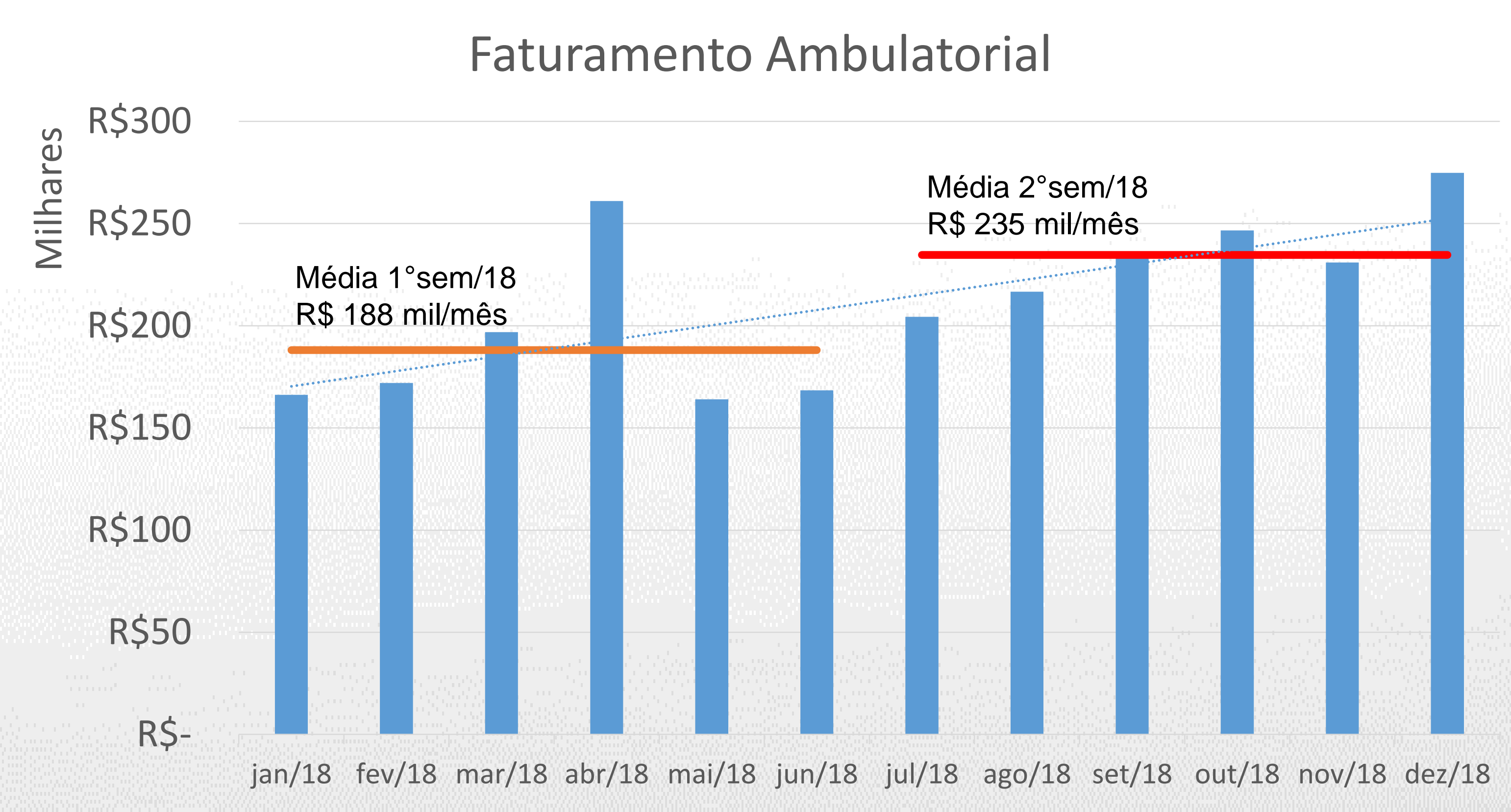

\section{Conclusão}

O projeto de revisão do processo de faturamento ambulatorial mostrou-se efetivo na melhoria dos apontamentos dos procedimentos realizados e contribuiu para o aumento do faturamento das divisões e do Instituto.

Bibliografia: MALIK, A. M., SCHIESARI, L.M.C. Qualidade na Gestão Local de Serviços e Ações de Saúde. Volume 3. São Paulo: Faculdade de Saúde Pública da Universidade de São Paulo, 1998. (Série Saúde \& Cidadania) 